\title{
Entre palavras e imagens: famílias negras no Museu Histórico de Londrina/PR (1970-2016)1
}

\section{Between words and pictures: black families in the History Museum of Londrina/PR (1970-2016)}

\author{
Cláudia Eliane P. Marques Martinez*
}

\begin{abstract}
Resumo
Este artigo busca compreender o significado das coleções doadas pelas famílias negras ao Museu Histórico de Londrina/PR (MHL) nos últimos dez anos. Em razão da ausência de objetos tridimensionais, selecionou-se, para esse estudo, o acervo audiovisual. Em relação às palavras (entrevistas e depoimentos) e às imagens (fotografias originais, negativos e reproduções digitais), um conjunto de questões foi proposto. Procurou-se, primeiramente, abordar a formação das referidas coleções com base na história do MHL. Posteriormente, o foco recaiu sobre aspectos relacionados às profissões, às relações sociais e a outras nuanças de vida das famílias escolhidas. O viés teórico-metodológico do presente trabalho não se insere na problemática da imagem na História, muito menos na análise do discurso. Embora essas vertentes sejam pertinentes, optou-se, aqui, por historicizar as coleções das famílias negras e tomar como referência regional e nacional a política de aquisição da mencionada instituição museal.
\end{abstract}

Palavras-chave: Famílias negras; cultura negra; Museu Histórico de Londrina; coleção; acervo Abstract
This article seeks to understand the meaning of the collections donated by
black families to the Historical Museum of Londrina / PR (MHL) over the
last ten years. Due to the absence of three-dimensional objects, we selected
the audiovisual collection for this study. In relation to the words (interviews
and testimonies) and the images (original photographs, negatives, and digital
reproductions), we proposed a set of questions. We first addressed the creation
of these collections based on the history of the MHL. Subsequently, we focused

\footnotetext{
${ }^{1}$ Este trabalho fez parte do projeto "Patrimônio cultural e museu: a história das coleções e do acervo do Museu Histórico de Londrina/PR (1970/2000)" recentemente concluído. Essa pesquisa contou com a participação de alunos do Curso de História, da Especialização em "Patrimônio e História" e do Mestrado em História Social, da Universidade Estadual de Londrina (UEL-PR).

* Doutora em História Econômica pela Universidade de São Paulo. Professora do Departamento de História, do Programa de Mestrado em História Social e da Especialização em "Patrimônio e História" da Universidade Estadual de Londrina. E-mail: cepmarques@uol.com.br
} 
on the aspects related to the professions, social relations, and other nuances of life of the chosen families. The theoretical-methodological preference of this study does not fit into the problematic of the image in History, nor in discourse analysis. Although these aspects are pertinent, we opted to historicize the collections of the black families and to take the acquisition policy of the museum as a regional and national reference.

Keywords: Black families; black culture; Historical Museum of Londrina; collection.

\section{Introdução}

As últimas décadas do século XX foram marcadas por uma ampla reformulação dos museus, preocupados, a partir de então, em dialogar e aproximar-se do público em geral. ${ }^{2}$ Além disso, seguindo uma tendência mundial, assistiu-se, no Brasil, à fragmentação das instituições museais, destinadas, agora, a temas e objetos cuja presença, nesses espaços, era antes inimaginável: imigração, língua portuguesa, moda, ofícios, perfumes, sapatos, som, futebol, cultura negra... - só para destacar alguns exemplos. ${ }^{3}$

Com base nesse cenário multifacetado, dinâmico e complexo que é o mundo dos museus, este artigo busca analisar as coleções e o acervo existentes no Museu Histórico de Londrina (MHL), mais especificamente aqueles relacionados às famílias negras. $O$ visitante ou o pesquisador que almejar estudar a cultura negra nessa instituição ficará surpreso (ou não?) com a falta de objetos tridimensionais - tanto na exposição de longa duração quanto no acervo da reserva técnica. Essa ausência não deixa de ser lamentável, haja vista a participação social, econômica e cultural do(a)(s) negro(a)(s) ao longo da história da (re)ocupação do Norte do Paraná, no século XX.

\footnotetext{
${ }^{2}$ POULOT, Dominique. Museu e Museologia. Trad. Guilherme João de Freitas Teixeira. Belo Horizonte (MG): Autêntica, 2013. SANTOS, Miriam Sepúlveda dos Santos. A escrita do passado em museus históricos. Rio de Janeiro: Garamond; Minc; IPHAN; DEMU, 2006.

${ }^{3}$ No artigo de Ulpiano Toledo Bezerra de Meneses intitulado Do teatro da memória ao laboratório da História: a exposição museológica e o conhecimento histórico (1994), é possível encontrar uma ampla discussão acerca do papel do museu na contemporaneidade. Essa discussão parte de duas premissas: 1) que possibilidade de participação do museu histórico pode haver na produção do conhecimento?; 2) como, nessa perspectiva, funciona a exposição museológica? (p. 15). Ver: MENESES, Ulpiano Bezerra Toledo de. Do teatro da memória ao laboratório da História: a exposição museológica e o conhecimento histórico. Anais do Museu Paulista. Nova Série, v. 2, 1994.
} 
No entanto, se recorrermos ao acervo audiovisual, um leque de possibilidades descortina-se diante do pesquisador interessado. Com efeito, entre as palavras (entrevistas e depoimentos) e as imagens (fotografias originais, negativos e reproduções digitais), muitas questões podem ser problematizadas. Dois conjuntos de indagações foram concebidos para a realização deste artigo.

O primeiro assenta-se sobre as problemáticas de caráter operacional, ou seja, busca-se compreender a formação do referido acervo com base na política de aquisição desenvolvida pela instituição museal em foco, ao longo de sua trajetória. Quando e como o acervo audiovisual foi constituído pelo Museu ao longo dos seus quarenta e oito anos de existência? Esse material sempre constituiu alvo da política de aquisição e das ações de preservação do MHL? As coleções de fotografias e entrevistas foram doadas por quais famílias ou indivíduos? Como as coleções foram organizadas, classificadas e sistematizadas? De que forma o acervo é posto à disposição do público em geral?

O segundo conjunto de problemas possui um caráter específico/qualitativo. Em outras palavras, procuramos perceber, por meio dos depoimentos, documentos e fotografias, as histórias das famílias negras selecionadas e, por consequência, a inserção do negro na cidade de Londrina. Cabe a pergunta: esse acervo e as coleções nele contidas permitem, de fato, entender aspectos pertinentes à história das famílias negras na cidade? Como elas se relacionavam (ou não) com os poderes político e econômico vigentes? A quais classes sociais essas famílias, grupos e/ou indivíduos negros pertenciam? É possível identificar nas falas (nas palavras) e nas fotografias (nas imagens) preconceitos explícitos e/ou velados?

A fim de tentar responder a esses conjuntos de questões, o presente artigo foi dividido em duas partes. Primeiramente, aborda-se, de forma breve e sucinta, a história da instituição, tomando como referência principal o papel dos diretores e as ações de preservação (e construção) da memória de Londrina. ${ }^{4}$ Busca-se compreender como e quando esse acervo - o das famílias negras - começou a fazer parte da política de aquisição da instituição enfocada. Num segundo momento, é apresentado ao leitor o acervo referente a tais

\footnotetext{
${ }^{4}$ Sobre a história da cidade e do MHL existe uma bibliografia significativa, fruto de teses de doutorado, dissertações de mestrado, livros e artigos científicos. Ver os trabalhos de: MATOS, Cláudia Eliza Marques de. Descortinando o Museu Histórico de Londrina pelos olhos do público: um estudo da concepção e a percepção do público espontâneo sobre a exposição de Longa Duração. Dissertação de Mestrado. Programa de Pósgraduação em História Social. Departamento de História. Universidade Estadual de Londrina. 2016.; SILVA, Priscilla Perrud. De Estação Rodoviária a Museu Histórico de Londrina: a trajetória do edifício - 1946-1986. 2012. Trabalho de Conclusão de Curso. (Graduação em História) - Universidade Estadual de Londrina (UEL).
} 
famílias, de forma a identificá-las e compreender aspectos relevantes de suas vidas, por intermédio dos depoimentos e das imagens por elas cedidos ao MHL.

É preciso esclarecer, antecipadamente, que o viés teórico-metodológico aqui adotado não se insere na problemática da imagem na História, muito menos na análise do discurso. Reconhece-se que ambas as vertentes metodológicas são importantes para o entendimento das palavras proferidas nos depoimentos, bem como para a compreensão das imagens doadas pelas famílias negras. No entanto, a preocupação principal deste artigo reside em apresentar, contextualizar e problematizar essas coleções, tomando como ponto de partida a instituição museal. Vejamos, então, o contexto da criação do MHL, na década de 1970, e como foi estabelecida a política de aquisição ao longo de sua trajetória.

\section{A história das coleções no Museu Histórico de Londrina: uma proposta de periodização}

Para entender aspectos que envolvem a história do MHL e a formação de seu acervo e de suas coleções, propomos pensar a instituição fundamentando-nos em quatro momentos distintos, embora não excludentes. A tese de Edson José Holtz Leme aponta uma classificação diferente da aqui apresentada. Nela é possível vislumbrar a história do MHL em três momentos distintos. ${ }^{5} \mathrm{O}$ primeiro vai da criação do museu, em 1970, até a transferência da instituição para o prédio da antiga estação ferroviária, em 1986. Um segundo momento abarca o período de 1986 a 1996, quando o museu fecha as portas para reforma e reestruturação de sua exposição. Por fim, há o período após a reabertura do MHL em 2000, fase essa que abrange os dias atuais. $O$ autor toma o espaço físico (além das exposições) como referência para pensar a instituição. Nossa proposta está pautada, sobretudo, no papel que os diretores desempenharam em suas gestões e, consequentemente, no olhar sobre a política de aquisição de acervo, considerando o âmbito regional e nacional.

Não iremos nos ater na análise deste artigo na questão de como as exposições temporárias foram realizadas durante a história da instituição. Também não é intenção deste texto verticalizar a discussão das fases mencionadas, mas demarcar e identificar, com base nessas etapas, a problemática levantada. Ou seja, pretende-se entender a ausência do negro em determinados momentos da história da instituição - e também o contrário, isto é, sua presença naquela instituição, a partir de um período específico.

${ }^{5}$ LEME, Edson José Holtz. O teatro da memória: o Museu Histórico de Londrina - 1959-2000. Tese de Doutorado. Unesp - Assis (SP), 2013. 


\section{A primeira fase: a gestão de Padre Carlos Weiss (1970 a 1976) e museologia da década de 1970}

O MHL foi criado em 18 de setembro de 1970. Dessa data até 1976, a instituição teve como diretor o padre e professor Carlos Weiss, que reuniu, coletou e sistematizou, juntamente com outros docentes e alunos dos cursos de História, Geografia e Antropologia, os primeiros objetos e coleções. Analisando o período e a documentação disponível no MHL sobre sua gestão, pôde-se constatar a ênfase dada por Weiss ao acervo e às coleções de caráter arqueológico e etnográfico. É provável que o fato de ele ser professor de História Antiga e Medieval da antiga Faculdade de Filosofia e Ciências Humanas, assim como sua atuação no Departamento de História, principalmente, tenha contribuído para essa postura.

Antes de adentrar na gestão de Weiss, vejamos as concepções de Lygia Martins Costa $^{6}$ no que se refere à museologia no Brasil. Percebe-se que a criação do MHL (1970) e a formação de suas coleções e acervos estavam em conformidade com a realidade brasileira no que tange aos museus. Exemplo dessa sintonia pode ser confirmada por meio das teses mencionadas pela autora no texto “Criação de museus regionais (1971)". A museóloga salienta o significado dos museus locais, pois "nem todo patrimônio nascido de uma região tem qualificação dessa amplitude". ${ }^{7}$ O que ela estaria chamando de amplitude? Seria, para a autora, o "caráter nacional" conferido a poucos museus brasileiros? Os exemplos extraídos do texto da pesquisadora possibilitam problematizar a questão anteriormente formulada.

Pelo conteúdo tanto histórico quanto artístico, os conjuntos formados em Minas
(Museu da Inconfidência - 1938 e o Museu do Ouro - 1945) e no Rio Grande (Museu
das Missões -1940) ultrapassam as balizas de expressão local para atingirem
simultaneamente um significadonacional. É que (tais museus) traduzem aspectos
dos ciclos socioeconômicos e circunstâncias políticas que o país em sua
pluralidade cultural viveu. Portanto, de implicação bem mais abrangente que
a região que lhes deu origem. O IPHAN intencionalmente manteve no próprio
meio os frutos ali gerados. Um jeito de despertar as comunidades para um

\footnotetext{
${ }^{6}$ Segundo informações coletadas no portal do Instituto Brasileiro de Museus (IBRAM), Lygia Martins Costa formou-se, em 1939, no primeiro Curso de Museus no Brasil, localizado no Museu Histórico Nacional. Posteriormente, trabalhou no Museu Nacional de Belas Artes e no Instituto do Patrimônio Histórico e Artístico Nacional, participou da implantação do Conselho Internacional de Museus (ICOM) no Brasil, em 1948, e representou o País na histórica Mesa Redonda de Santiago, realizada em 1972, que consagrou, entre outras questões, as teses da Museologia Social. Ver:<https://www.museus.gov.br/tag/lygia-martins-costa/>. Acesso em: 6 de novembro de 2015.

${ }^{7}$ COSTA, Lygia Martins. Criação de museus regionais (1971). De Museologia, Artes e Políticas de Patrimônio. (Pesquisa: Clara Emília Monteiro de Barros) Rio de Janeiro: IPHAN, 2002. p. 28.
} 
orgulho da obra de seus ancestrais; como uma tomada de consciência do que foram e do que contribuíram para a formação e fisionomia nacionais. ${ }^{8}$

Alguns pontos ficam evidentes no trecho selecionado. A preocupação em definir a identidade nacional, por intermédio dos museus, é uma delas. Outra questão importante é que o entendimento da História passava, sobretudo, pelo viés econômico. Talvez, por isso, Costa utilize, a fim de justificar e classificar os museus em "nacionais" ou "regionais", os chamados "ciclos econômicos" (pau-brasil, cana de açúcar, ouro, etc.). Desconfiamos que, por trás dessas categorizações, estejam subjacentes interesses políticos, econômicos e geográficos; afinal, priorizavam-se determinadas localidades em detrimento de outras.

Exemplos dessas seleções e classificações ficam evidentes quando a estudiosa discorre sobre a quantidade, a distribuição geográfica, as áreas de maior concentração e o tipo de coleção privilegiada pelos museus brasileiros, em especial os de caráter regional:

Quanto à sua distribuição geográfica, eles (os museus) existem em todos os estados, principalmente em São Paulo, na Guanabara, em Minas Gerais, no Rio Grande do Sul, na Bahia e em Pernambuco, e estão localizados em numerosos municípios, que, por razões diferenciadas, tomaram a iniciativa de sua criação. [...] De um modo geral as coleções regionais são ecléticas, nas quais a documentação histórico-artística local se confunde com o folclore, a etnografia indígena, arqueologia e coletânea de ciências naturais. Mas isso não se dá nos grandes museus. ${ }^{9}$

Voltando à discussão que envolve diretamente as coleções ao MHL, observa-se que, além das peças arqueológicas e etnográficas recebidas por meio doação e/ou compra, são numerosos os objetos trazidos pelos estudantes dos cursos de História e Geografia, grande parte deles alunos de Weiss, como se pode denotar do Primeiro Livro de Registro.

Foram doados para a sessão arqueológica deste Museu diversos objetos achados ocasionalmente por moradores desta Região Norte do Paraná em suas lavouras e trazidos por diversos estudantes: 14 Machados de pedra, 49 potes de barro grande, 57 tigela de barro, 13 pedras polidas. ${ }^{10}$

Neste documento, escrito à mão pelo Padre Weiss e por sua secretária, Marina Zuleika Scalassara, encontram-se informações detalhadas acerca dos

\footnotetext{
${ }^{8}$ COSTA, op. cit., 2002, p. 27-28, grifos nossos.

${ }^{9}$ Ibidem, p.41, grifos nossos.

${ }^{10}$ Primeiro Livro de Registros, Museu Histórico de Londrina, 1971.
} 
objetos, como os que "foram doados ao Museu pelo Sr. Baltazar José Costa: um ouriço, uma preguiça e uma queixada, animais empalhados por ele mesmo" ${ }^{11}$. A lista de artefatos é extensa e traz não só a descrição qualitativa do artefato doado, recolhido ou achado, mas sua quantidade, data e autor da doação.

Ao lado de animais taxidermizados, fósseis, machados de pedra e artefatos indígenas, encontravam-se também almofarizes, pilões, máquinas de moer e de escrever, ferros de passar roupa, telefones, indumentárias, sapatos, bruacas, chaleiras, panelas, xícaras, bules.

Aqui cabe uma observação que remete à formação das instituições museais brasileiras, na década de 1970. Como afirmamos anteriormente, os museus históricos acabavam constituindo acervos e coleções de caráter multifacetado e "eclético". A diversidade de objetos e artefatos que caracteriza o PLR é decorrente também de doações heterogêneas resultantes das coleções particulares, a exemplo de uma "cabeça de índio" que se inclui entre "Figuras em luta "Uca-uca" e outros itens, como a listagem demonstra:

Foram doados por D. Margarida Kato os seguintes objetos:

3 fósseis de animais (g 35-36-37) 12

2 pedaços de coral BR -12

2 pedaços de madeira petrificada (g38-39) - 11

1 estojo contendo amostras de minérios - 11 ou 14

6 cacos de cerâmica arq 146 a 151 - 2

1 tigela de cerâmica - 2

4 cristais de rocha -12

1 pedra c/ invólucro lítico (?) - 12

1 pedaço de raiz de madeira

8 pauzinhos de incenso chinês -6

1 foice japonesa para cortar papel -6

1 coité - 53 balas de revólver

1 ponta de flecha arq $145-2$

Cabeça de índio 7/149

10 máquinas fotográficas

4 flashs

28 caixas de fósforos estrangeiros doado ao Dr. Wilmo

2 macinhos de cigarros doado ao Dr. Wilmo

Figuras em luta "Uca-uca"

Registrados, fichados e numerados em 11/06/75.

${ }^{11}$ Primeiro Livro de Registros, Museu Histórico de Londrina, 1971, verso da p. 8. 
É importante observar que, além de artefatos arqueológicos, objetos do cotidiano e do trabalho, Pe. Carlos Weiss, dava atenção especial aos objetos e artefatos pertencentes, também, a outras culturas brasileiras, com destaque para a nordestina. As várias viagens ao interior do Brasil realizadas por Weiss, com o intuito de adquirir peças, atestam sua preocupação. ${ }^{12}$

Seguindo a linha do tempo, ressalta-se que, em 1974, a instituição tornou-se órgão suplementar da Universidade Estadual de Londrina (UEL) e foi vinculada academicamente ao Departamento de História (DH) do Centro de Letras e Ciências Humanas. Primeiramente funcionou, de forma precária, no porão do Colégio "Hugo Simas", e, somente em 1986, o acervo existente foi transferido para o prédio da antiga Estação Ferroviária, tornando-se não só um Museu Histórico com sede própria, mas também uma referência cultural para a cidade e a região norte do estado do Paraná. ${ }^{13}$ Cabe salientar que o MHL foi pensado a partir de duas perspectivas: $1^{1}$ ) a regional, por se tratar de um órgão cujo foco principal é a história da cidade de Londrina e região; $2^{\mathrm{a}}$ ) a universitária, uma vez que a sua criação teve, como ponto de partida e apoio principais, os Departamentos de História, Geografia e Antropologia.

Nesse sentido, Lygia Martins Costa foi assertiva ao dizer que uma das características dos museus regionais era, exatamente, a formação de coleções ecléticas e heterogêneas. ${ }^{14}$ Etnografia, arqueologia, animais taxidermizados, bules, chaleiras e, no caso do MHL, uma "cabeça de índio" conviveram, simultaneamente, no mesmo espaço; a despeito dos conflitos e disputas inerentes às redes de poder que, paulatinamente, iam constituindo-se.

Trabalhamos, aqui, com a hipótese de que, com a morte de Carlos Weiss, em 1976, o interesse em relação à tipologia e à natureza dos objetos que deveriam ficar ou não no MHL sofreu modificações significativas. A etnografia, a arqueologia e a ênfase dada a outras etnias e grupos sociais, presente nos momentos iniciais da fundação do Museu, foram aos poucos perdendo

\footnotetext{
${ }^{12}$ Do mesmo modo, podemos salientar a vinda para o MHL de um sambaqui doado ao Departamento de Antropologia, alguns anos antes da criação do MHL, pelo Museu de Arqueologia e Artes Populares de Paranaguá/PR.

${ }^{13}$ O MHL foi transferido para o prédio atual, a antiga Estação Ferroviária, somente em 1986, quando esta foi desativada. A edificação que abrigava a estação foi concedida, em regime de comodato, pela Prefeitura de Londrina - situação que prevalece até a atualidade. Para mais informações, consultar o trabalho de Priscila Perrud Silva (2012), o qual analisa a ocupação, a reestruturação e a ressignificação da antiga Estação Ferroviária como um Museu Universitário. Já a Universidade Estadual de Londrina foi criada em 28 de janeiro de 1970. Em 1973, o Departamento de História e demais cursos ligados às Ciências Humanas, que funcionavam no Colégio "Hugo Simas", foram transferidos para o campus recentemente inaugurado. Ver o trabalho de: SILVA, Joaquim Carvalho. Peroba-Rosa - UEL 25 anos. Londrina (PR): Eduel, 1996.
}

${ }^{14}$ COSTA, op. cit., 2002. 
dimensão e importância dentro da referida instituição. Seguindo movimento contrário, a figura do "pioneiro" e a história da (re)ocupação recente no século XX passaram a ganhar espaço cada vez maior nas exposições e na política de aquisição de acervos e coleções, como se poderá constatar a seguir.

\section{A segunda fase, de 1976 a 1996: o "pioneiro" constitui o centro e a periferia do MHL}

O segundo momento - e o mais longo deles - refere-se ao período que vai do falecimento de Carlos Weiss, em 1976, até 1996, quando o MHL fecha suas portas para a restauração e a reformulação da exposição. Nesse período de 20 anos, apenas dois diretores estiveram à frente da instituição. Conceição Geraldo geriu o MHL em duas ocasiões distintas: de agosto de 1976 a março de 1979 e de 1994 a junho de 2002. Olympio Westphalen assumiu a diretoria no intervalo temporal que vai de 1979 a 1994. Durante essa fase, mais precisamente em 1986, o Museu foi transferido do porão do Colégio "Hugo Simas" para o prédio da antiga Estação Ferroviária, lugar que ocupa até hoje.

Como assinalado anteriormente, partimos do pressuposto de que a partir da morte de Weiss (1976) e a ascensão dos dois diretores já citados, a política de aquisição e preservação do acervo e das coleções passou a ter prioridades e interesses distintos dos daqueles anos iniciais do MHL. Outro fator que não deve ser menosprezado, embora externo em relação aos muros do museu, tem a ver com a crise econômica ocasionada pela geada negra, ocorrida em 18 de julho de 1975. A nosso ver, a crise então desencadeada e a reorientação dos paradigmas econômicos no final da década de 1970 causaram impactos significativos na política referente ao acervo e às coleções do MHL. A cidade de Londrina perde sua referência como capital do café e, em seguida, mergulha em uma crise econômica e de identidade.

Para "recuperar" uma identidade profundamente abalada pelo colapso financeiro tornou-se necessário enaltecer e forjar figuras míticas, como a do "pioneiro". ${ }^{15} \mathrm{E}$, em decorrência disso, foi preciso construir um discurso que exaltasse a saga desses intrépidos homens, o que se tornou, então, o ponto central da discussão sobre a "origem" e o "progresso" da cidade e sua região. Dessa forma, as coleções de arqueologia, etnografia e história natural tornaram-se quase obsoletas, assim como as relativas a outras etnias e grupos sociais. ${ }^{16}$ Os

\footnotetext{
${ }^{15}$ ADUM, Sônia M. S. L. Práticas Discursivas, Patrimônio e Memória: Monumento Memorial do Pioneiro. In: SILVA, Cláudia; MORAES, Vanda (Orgs.) Encontro Cidades Novas: a construção de políticas patrimoniais. Londrina: Edição Humanidades, 2009.

${ }^{16}$ Pertenceria a esse momento a transferência de parte do acervo arqueológico para o Museu de Geologia da UEL.
} 
indígenas, os nordestinos e, principalmente, os negros continuaram sem um espaço significativo dentro do Museu, isto é, sem um ambiente que os acolhesse como personagens centrais da engrenagem histórica. A mencionada tríade étnica foi, assim, escamoteada da expografia e do processo histórico até o começo do século XX, como vamos tentar demonstrar ao longo deste artigo.

Em particular, importa ressaltar que, diferentemente dos indígenas e nordestinos, os quais receberam, na gestão de Pe. Weiss, certa atenção, as coleções e o acervo referentes à cultura negra foram sumariamente negligenciados durante quase toda a trajetória do MHL, sendo lembrados em pouquíssimas ocasiões, como nas exposições temporárias.

\section{A terceira fase (1996 a 2002): preparando-se para a abertura da exposição de longa duração}

De 1996 a 2000, o MHL literalmente fechou suas portas. Iniciam-se o processo de reforma e, principalmente, o de reformulação da exposição, que teve Maria Cristina Bruno como curadora principal. Todo o processo ocorreu na gestão de Conceição Geraldo, que ficou à frente do museu até 2002. A exposição "possível" foi inaugurada em dezembro de 2000 e teve como objetivo angariar e dar visibilidade ao acervo e aos objetos que representassem a história da reocupação da região de Londrina, a partir da vinda da Companhia de Terras Norte do Paraná (CTNP), na década de 1920.

A representação histórica visou, principalmente, destacar as famílias pioneiras que reocuparam o norte paranaense no século XX. Os indígenas ganharam uma pequena sala na entrada da exposição, que recebeu o nome de Prefácio. Além de objetos arqueológicos e líticos, é possível identificar, nesse pequeno módulo, mapas e um painel com informações a respeito do "sertão do Tibagi". O texto contido em um mural ${ }^{17}$ da exposição informava, entre outras questões, que aquelas terras, no começo do século XX, eram devolutas e desprovidas de ocupantes. Os índios sobreviventes das guerras do passado agora habitavam reservas ou tinham se refugiado no Paraguai.

Se, para o indígena, quanto a sua representação, coube a "Pré-história", para os negros restou apenas o silêncio. Nenhum objeto tridimensional, nenhuma palavra dita, imagens esparsas... De formas diferentes, as culturas indígena, nordestina e negra foram negligenciadas na Nova Exposição. Nessas

\footnotetext{
${ }^{17}$ Entre os dias 27 de junho e 2 de julho de 2016, o MHL organizou e sediou o Seminário Culturas Indígenas e Acervos Museológicos do Norte do Paraná. O evento teve ampla participação de indígenas, que, ao final do evento, em um ato simbólico, cobriram o mural de preto e, num pequeno texto escrito à mão, reafirmaram a presença da etnia, tanto no passado quanto no presente.
} 
quase três décadas - de 1976 a 1996 -, também não fizeram parte da política de constituição de acervo e de coleções do Museu objetos e artefatos que não estivessem relacionados à história da (re)ocupação do Norte do Paraná, no século XX. Embora algumas exposições dedicadas aos negros, indígenas e nordestinos tenham sido realizadas nesse período, pode-se afirmar, com relativo grau de certeza, que tais ações tiveram um caráter pontual e esporádico.

\section{A quarta fase (2002...): da mudança político-administrativa à mudança dos paradigmas}

Com a saída de Conceição Geraldo da direção, em 2002, a instituição inicia outra fase, cuja duração, segundo a perspectiva adotada aqui, engloba os dias atuais. Segundo Leme, apesar de o diretor que sucedeu Geraldo, José César Reis (2002 a 2006), não ter realizado nenhuma modificação expressiva na exposição de longa duração, nem no acervo, mudanças significativas ocorreram

[...] em sua política de aproximação com o Departamento de História, ampliando-se o número de estagiários do curso no Museu, o retorno, com maior assiduidade, da representação do museu nas reuniões do Departamento e Conselho do CLCH, além de uma maior abertura nas exposições temporárias, por temas e personagens até então não contemplados pelo museu. ${ }^{18}$

A gestão seguinte foi a de William Reis Meirelles, que se manteve na direção por um curto período, entre 2007 e 2008. Edson Holtz Leme destaca que as coordenações, tanto do Arquivo Histórico/CDPH quanto do MHL, sempre tiveram os professores de história como seus gestores. "No Museu a única exceção ocorreu por um curto período de tempo, entre outubro de 2007 e janeiro de 2008, quando Débora Martins, docente do curso de Educação Física e então assessora especial da Reitoria, dirigiu o Museu, de forma interina, após o afastamento, pelo reitor, do historiador William Reis Meirelles". ${ }^{19}$

As relações entre o Departamento de História e o Museu sempre foram marcadas por uma certa dose de tensão. Ainda segundo Leme, os conflitos davam-se em virtude das diferentes perspectivas quanto à concepção de História.

Enquanto o CDPH, especialmente no final dos anos 1980 e durante a década de 1990, abriu conceitualmente seu acervo, para as novas abordagens e perspectivas teóricas advindas das transformações por que passava a historiografia no Brasil, fruto dos ecos dos debates da historiografia francesa, sobretudo da escola dos

\footnotetext{
${ }^{18}$ LEME, op. cit., 2013, p. 147.

${ }^{19}$ Ibidem, p. 167-168.
} 
Analles, e também do marxismo, o Museu mantinha-se fiel a uma perspectiva mais tradicional. ${ }^{20}$

O restabelecimento das relações entre DH e MHL, após a curta cisão ocorrida em 2007/2008, concretizou-se com a direção da professora de História Medieval Angelita Marques Visalli (2008-2012). Visalli conseguiu não só apaziguar a situação entre o Museu, o Departamento de História e a Reitoria, como fazer com que sua gestão assumisse uma posição conciliadora e de aproximação efetiva com relação aos professores do DH. Essa proximidade se deu mediante várias frentes de trabalho, que resultaram em exposições e projetos, desenvolvidos, principalmente, com professores e alunos do curso de História.

Tanto na gestão de Visalli quanto na direção atual, exercida pela professora Regina Alegro, é possível identificar ações e políticas voltadas para os grupos antes não contemplados dentro da instituição. Exposições temporárias com temas relacionados à Folia de Reis (2008), à "Memória da Saúde em Londrina" (2012), aos indígenas (2013), bem como seminários, cursos e eventos voltados para as culturas indígena, nordestina e negra, têm sido desenvolvidos e apresentados ao público. É importante sublinhar que foi com essas últimas duas gestões, sobretudo, que novas ações puderam ser identificadas, especialmente no que tange às culturas indígena e negra. Essas atuações repercutiram diretamente na política de aquisição de acervo e das coleções do MHL, conforme se poderá verificar adiante.

\section{Entre palavras e imagens: famílias negras no Museu Histórico de Londrina}

A ausência de objetos tridimensionais representativos da cultura negra constitui um dos grandes gargalos para o estudo do grupo social negro, tomando como referência o Museu Histórico de Londrina. Nem seria necessário dizer que a etnia teve ampla participação social, econômica e cultural na (re) ocupação recente - durante o século XX - do norte do Paraná. Então, como conhecer o cotidiano desses homens e mulheres que trabalharam, viveram e construíram suas histórias, com base em subsídios oferecidos pelo MHL? Como descortinar as relações familiares, saber de suas alegrias e agruras? Como identificar o preconceito sofrido, ou não, ao longo de suas vidas?

Palavras e imagens foram os dois pilares que permitiram refletir sobre a história da cultura negra dentro do Museu Histórico de Londrina. É com

${ }^{20}$ Ibidem, p. 169. 
esse acervo cartorial - intramuros - que iremos alinhavar algumas questões, a respeito não somente da presença, mas também da ausência negra naquele espaço. Estamos apropriando-nos do conceito de acervo cartorial (intramuros) de Ulpiano Toledo Bezerra de Meneses, pois a ideia expressa muito bem a proposta de estudo aqui desenvolvida.

Como acervo cartorial o autor concebe aqueles documentos "organizado[s] e construído[s] por tudo aquilo que remeter à cidade" - no caso deste artigo, o negro. Já o acervo operacional, extramuros, seria aquele em que a cidade poderia contribuir e comunicar-se com o museu. ${ }^{21} \mathrm{O}$ que queremos enfatizar é o fato de existir um universo documental vasto e diversificado para pensar a cultura negra na cidade, um universo extramuros, para além do Museu. Poderíamos elencar uma série de fontes - periódicos, revistas, imagens, inventários, processos crimes, etc. -, institutos e entidades, como a Associação Recreativa Operária de Londrina (AROL), o Instituto Brasileiros de Geografia e Estatística (IBGE), o jornal Folha de Londrina, o Movimento Negro, entre outras instituições e sociedades - que poderiam fornecer dados e informações substanciais para o tema em questão.

No entanto, como já sublinhado, vamos nos ater ao acervo que se encontra hoje no MHL, de forma a evidenciar, primeiramente, como essas coleções foram se constituindo. Em seguida, vamos continuar o estudo de uma temática já mencionada neste artigo, isto é, as famílias negras no MHL, sublinhando as lacunas e as ausências desse grupo social dentro da instituição, pois na perspectiva histórica o silêncio gera ecos e produz, também, discursos.

Se, de um lado, a ausência de objetos tridimensionais relacionados à cultura negra constitui um fator frustrante, de outro, o pesquisador se surpreende ao se deparar com o acervo audiovisual. Deve-se destacar, inicialmente, antes de enfocar as famílias negras propriamente ditas, que a documentação audiovisual do MHL é extremamente complexa, vasta e multifacetada. Nela é possível identificar distintos grupos sociais, diversas etnias (brancos, negros, indígenas, etc.), bem como abordar variados temas, assuntos, paisagens, culturas e pessoas.

Segundo informações do Setor Imagem e Som - Eugênio Brugin, existe hoje, no MHL, um acervo imagético de aproximadamente 80.000 itens. Entre estes, há fotografias originais, negativos de vidro e flexíveis, filmes de 16 e $35 \mathrm{~mm}$, slides, discos, reproduções digitais, além de depoimentos e entrevistas.

\footnotetext{
${ }^{21}$ MENESES, Ulpiano Toledo Bezerra de. 0 museu de cidade e a consciência da cidade. Seminário Internacional "Museu e Cidades". Livro do Seminário Internacional. Organização: Afonso Carlos Marques dos Santos, Carlos Kessel, Cêça Guimarães. Rio de Janeiro: Museu Histórico Nacional, 2004, p. 258.
} 
Desse total, 30.000 estão devidamente catalogados e disponíveis ao público em geral. $^{22}$

Homens, mulheres e crianças da etnia negra estão representados de duas formas no interior dessa vasta reunião de imagens. Quanto à primeira maneira de representação, podemos ressaltar que os itens relativos aos negros encontram-se dispersos, de forma aleatória, nos vários conjuntos documentais de famílias não negras, como, por exemplo: a coleção de imagens doadas pela Prefeitura de Londrina; a coleção conhecida como Foto Estrela; as coleções referentes aos fotógrafos José Juliani e Armínio Kaiser, etc. No mundo do trabalho, os negros marcaram presença significativa, como se pode observar na coleção de Amadeo Boggio, em que dezenas deles - cozinheiros, breneiros, operários - são fotografados trabalhando na estrada de ferro São Paulo-Paraná, mais especificamente no trecho Cambará-Londrina. ${ }^{23}$

A segunda forma de representação do negro no MHL pode ser vista nas coleções doadas pelas próprias famílias negras. Tais doações foram realizadas em decorrência de uma iniciativa do próprio museu, nas últimas gestões, durante o século XXI. Se o acervo audiovisual sempre fez parte da política de aquisição da instituição, as famílias negras fizeram-se presentes de forma verticalizada e específica muito recentemente, como já apontamos ao longo desse artigo.

Antes de conhecer as referidas coleções, torna-se necessário fazermos uma pequena digressão a fim de salientar que, ainda hoje, quando o negro é representado ${ }^{24}$ nos museus, acaba, na maioria das vezes, assumindo um caráter de vítima ou de herói (por exemplo: o Zumbi dos Palmares, Aleijadinho, lideranças negras, etc.). ${ }^{25} \mathrm{~A}$ historiografia concernente aos afrodescendentes no Brasil - seja aquela relacionada à escravidão, sejam os aspectos socioculturais - consolidou-se há mais de trinta anos, mas o mesmo não se pode dizer da expografia e da política de aquisição dos museus em geral.

Exemplo disso é o caso do Museu da Inconfidência/MG. Mesmo após ampla reformulação de sua exposição, em 2006, essa continuou abordando o

\footnotetext{
${ }^{22}$ Gostaria de agradecer à funcionária responsável pelo Setor Imageme Som - Eugênio Brugin, Célia Rodrigues de Oliveira, que gentilmente selecionou e disponibilizou a documentação consultada e utilizada neste artigo. ${ }^{23} \mathrm{O}$ mesmo pode ser dito com respeito às coleções Luiz Muraska e Camilo dos Anjos, entre outras.

${ }^{24}$ Sobre a representação do passado em museus históricos há uma ampla historiografia que aborda diretamente o tema. Ver principalmente: Censo, mapa, museu. In: ANDERSON, Benedict. Comunidades imaginadas. São Paulo: Companhia das Letras, 2008. SANTOS, Myriam Sepúlveda dos Santos. A escrita do passado em museus históricos. Rio de Janeiro: Garamond, Minc, IPHAN, DEMU, 2006.

${ }^{25}$ Sobre o lugar do negro nos museus brasileiros ver o trabalho de LODY, Raul. o negro no Museu Brasileiro. Construindo identidades. Rio de Janeiro: Bertrand Brasil, 2005.
} 
negro unicamente pelo viés da vitimização. ${ }^{26}$ Também, em duas importantes instituições cariocas, Myriam Sepúlveda dos Santos menciona que "se no Museu Nacional de Belas Artes encontramos silêncio e exclusão do negro, no Museu da República nos deparamos com o enaltecimento do negro em práticas populares como samba, carnaval e futebol". ${ }^{27}$

Em 2004, o Museu Histórico Abílio Barreto, em Belo Horizonte, inaugurou uma exposição de curta duração intitulada "Uma questão de raça: representações do Negro no Museu da Cidade", exatamente, para tentar "entender e reverter a situação concreta de não representação de elementos negros e afrodescendentes, como sujeitos, no acervo do MHAB e as possíveis implicações desta escolha". ${ }^{28}$

É preciso destacar, ainda, que a representação do negro em instituições museais dedicadas exclusivamente à sua história não costuma ser diferente, no que tange aos estereótipos culturais e/ou ao viés da vitimização. A exposição presente no Museu Afro-Brasileiro da Universidade Federal da Bahia, destacada por Myriam Sepúlveda dos Santos, constitui uma das poucos exceções.

Bastante distante de outros museus dedicados ao negro no Brasil, este museu (Museu Afro-brasileiro) não traz imagens de tortura, não enfatiza a escravidão e procura resgatar as contribuições positivas feitas por descendentes de africanos no Brasil. ${ }^{29}$

Depreende-se dessa análise que, nas instituições museais em geral, em especial os museus históricos, pouco, ou quase nada, é dito sobre cultura, cotidiano, famílias, homens e mulheres negro(a)s. Ou, quando essa fala se apresenta, torna-se difícil escapar dos clichês ou imagens pré-concebidas desse grupo social. O MHL, infelizmente, não fugiu à regra e só recentemente - nos últimos dez anos, aproximadamente - começou a rever e reverter esse quadro no que tange à política de aquisição. $\mathrm{O}$ acervo audiovisual das famílias negras no MHL

\footnotetext{
${ }^{26}$ ALVES. Rafael da Silva. Lendo o Museu. Relações entre a expografia e a historiografia no Museu da Inconfidência - Ouro Preto/MG. Dissertação de Mestrado. Programa de Pós-graduação em História. Faculdade de Filosofia, Letras e Ciências Humanas, Universidade Federal de Minas Gerais, 2014.

${ }^{27}$ SANTOS, Myriam Sepúlveda dos. Canibalismo da Memória: o negro nos museus brasileiros. Revista do Patrimônio Histórico e Artístico Nacional. Brasília/DF: IPHAN, N. 31, 2005. P. 51.

${ }^{28}$ BARBOSA, Nila Rodrigues. O não-lugar do negro no acervo museológico: problemas e perspectivas. In: GUIMARÃES, Manoel Luiz Salgado \& RAMOS, Francisco Régis Lopes. (Organizadores). Futuro do Pretérito. Escrita da História e História do Museu. Fortaleza: Instituto Frei Tito de Alencar / Expressão Gráfica Editora, 2010. p. 276.

${ }^{29}$ SANTOS, 2005, p. 41. A título de mais exemplos destacam-se três museus que tratam exclusivamente das culturas africanas e sua presença na formação da cultura brasileira: 1) Museu Afro Brasil, situado na cidade de São Paulo; 2) Museu do Negro, localizado no centro da cidade do Rio de Janeiro; 3) Museu da Abolição, em Recife/PE.
} 
não chega ainda a ser expressivo em termos de quantidade, mas adquire um significado simbólico, considerando-se a trajetória da instituição. Constitui, enfim, um divisor de águas na política de aquisição, pois se consolida um novo paradigma para a reflexão sobre os diferentes grupos sociais.

Em virtude da insuficiência de espaço disponível para apresentar as coleções das famílias negras no MHL, dividimo-las em duas partes, pois entendemos que, mesmo numericamente pequenas, elas permitem duas tipologias distintas. O primeiro conjunto documental - imagens, entrevistas, documentos e bibliografia - incide sobre as famílias negras que se sobressaíram de alguma forma no meio social e cultural de Londrina. Em uma linguagem coloquial, trata-se daqueles homens que "deram certo" e, em geral, já fazem parte do imaginário social presente na cidade, entre brancos e não brancos. Dentre eles, destacamos dois homens, o Doutor Preto e o Reverendo Jonas, que representam um imaginário social de luta, perseverança e redenção pelo trabalho e pelo esforço pessoal.

Justiniano Clímaco da Silva (1908-2000), o Doutor Preto, como ficou conhecido, foi uma personagem importante na cidade. ${ }^{30}$ Baiano de origem, o médico negro veio para Londrina a fim de exercer sua profissão, em 1938. Tornou-se especialista no combate a doenças infectocontagiosas, como a malária e a febre amarela. (Re)conhecido como o primeiro médico negro na cidade, exerceu não só a medicina, mas também enveredou pelo campo da política, chegando a se eleger deputado estadual pelo Partido Social Democrata, em 1947.

É possível localizar tanto dados biográficos a seu respeito quanto uma série de artigos de jornal em que ele é personagem. Destaque também seja dado a um pequeno conjunto formado por seis fotografias. Em uma delas, Doutor Preto aparece junto ao Presidente Eurico Gaspar Dutra, quando este visitou Londrina na década de $1940 .{ }^{31}$ Além desse material cartorial/intramuros, encontra-se, na exposição de longa duração, o jaleco branco com o qual o médico clinicava em Londrina, embora essa informação não conste em nenhum suporte da vitrine onde está exposta hoje essa indumentária.

O Reverendo Jonas Dias Martins (1902-1986) constitui outro ícone entre os personagens conhecidos e venerados no imaginário popular. ${ }^{32}$ Veio para Londrina nos anos 1930 e trabalhou na evangelização até sua morte, em 1986. A vida do Reverendo mistura-se com a história da fundação da cidade (1934) e

\footnotetext{
${ }^{30}$ SILVA, Maria Nilza; PANTA, Mariana. O Doutor Preto. Justiniano Clímaco da Silva. Londrina: UEL, 2010.

${ }^{31} \mathrm{O}$ conjunto de imagens em que o Dr. Clímaco aparece está localizado na Coleção Geral, Acervo MHL.

${ }^{32}$ LIMA, Éber Ferreira Silveira. Apóstolo Pé Vermelho. Jonas Dias Martins e a evangelização no norte do Paraná. São Paulo: Pendão Real, 2002.
} 
com a da Primeira Igreja Presbiteriana de Londrina, que ele ajudou a fundar, em 1937. A participação social e política também marcou sua vida e seu pastorado. Segundo o depoimento de sua filha Delmar Ferreira Martins, localizado no MHL, a vida do pai foi marcada pela generosidade e pelo espírito missionário. Na década de 1930, conta Delmar, todo o trabalho de evangelização foi realizado em cima do lombo de uma égua chamada Bolívia. Ainda de acordo com a filha, "o pai chegava a ficar até 40 dias longe de casa percorrendo as estradas, as casas e cidades do interior do Paraná". ${ }^{33}$

O médico e o pastor são exemplos de homens socialmente reconhecidos e que, de certo modo, já fazem parte do imaginário da cidade. Entretanto, nos últimos anos o MHL tem se dedicado a coletar documentos, recolher e receber materiais relativos a personagens que exerceram funções/atividades ligadas a profissões como barbeiro, ferroviário, músico, militar, etc.

O segundo conjunto documental ao qual nos referimos interessa especialmente a este artigo. Não queremos dizer com isso que os dois exemplos citados anteriormente não sejam relevantes. Mas abordar pessoas comuns, ou seja, aquelas que não fizeram parte de círculos sociais e culturais (re)conhecidos, permite refletir sobre o cotidiano de outras centenas, ou mesmo milhares, de cidadãos e cidadãs que também passaram pelas experiências da vida, da morte, da lembrança e do esquecimento.

Assim, a trajetória de Athanázio Soares de Almeida (1928-2007), trabalhador da Rede de Viação Paraná-Santa Catarina, constitui um exemplo digno de nota. A coleção recentemente doada ao MHL, em 14 de março de 2016, pelo filho Idalto José Mujimo de Almeida, é uma das mais completas e interessantes. Com esse material imagético e documental à disposição, foi possível acompanhar, mesmo que de forma fragmentada, a trajetória da família Almeida. Mais que isso: foi possível constatar que o acervo do Sr. Athanázio constitui um exemplo de como essas coleções são relevantes, na medida em que permitem conhecer aspectos do cotidiano e do mundo do trabalho dos homens comuns, que viveram uma vida simples, sem prestígio social e/ou político. É essa simplicidade que os faz, hoje, atores de uma história digna de ser aqui lembrada e (re)conhecida.

\footnotetext{
${ }^{33}$ Depoimento de Delmar Ferreira Martins, realizado em fevereiro de 2016 para o Acervo MHL. Outros exemplos de homens negros socialmente reconhecidos pela sociedade londrinense podem aqui ser lembrados. Um deles é o Dr. Oscar Nascimento, advogado que ainda exerce a profissão na cidade. Embora o MHL tenha a entrevista concedida por ele em 2013, além de um acervo, também doado por ele - principalmente reproduções digitais da AROL (Associação Recreativa Operária de Londrina) -, optamos por discorrer aqui apenas sobre as coleções que foram doadas por familiares depois do falecimento dos personagens em foco. O mesmo pode ser dito com relação ao Sr. José Bispo dos Santos, músico e militar.
} 
A coleção Athanázio Soares de Almeida é formada por um conjunto misto de fotografias/reproduções digitais e documentação pessoal/curricular. Das cinquenta reproduções digitais fornecidas ao MHL, metade delas mostra essa personagem entre seus familiares, amigos e colegas de trabalho. Outra parte significativa do conjunto é constituída por cartões postais da cidade de Londrina, assim como os documentos referentes ao período que passou no exército. As visitas e passeios realizados com a família, em sua cidade natal, Jaguariaiva/PR, também receberam atenção e destaque no conjunto de imagens.

Na coleção curricular/pessoal de Athanázio, identificamos 18 reproduções digitais, como as dos seguintes documentos: diploma do Curso Primário (concluído em 1940); carteira de identidade; certificado de reservista (retirado em 1946); contratos de trabalho e documentos do período em que trabalhou na Rede Ferroviária. Em relação a esse conjunto de informações que registram a vida civil de um indivíduo, Solange Lima e Vânia Carvalho nos lembram que:

\begin{abstract}
A intenção de homenagear pode ser observada em inúmeras doações "curriculares", ou seja, aquelas formadas por carteiras de identidade, passaportes, títulos de eleitor, brevês, certificados, nomeações, certidões, licenças de trânsito, diplomas (de titulação acadêmica, de premiação, de maçonaria, de homenagem, de associação), mas também de medalha, troféus, distintivos, suvenires de eventos públicos e políticos e comendas. Completam esta tipologia, recortes de jornais que narram os acontecimentos excepcionais ligados à trajetória de vida do doador e, por eles, ou pelos familiares, reunidos em uma espécie de clipping. ${ }^{34}$
\end{abstract}

A vida desse homem em destaque foi marcada pelo trabalho na Rede Ferroviária. Aos dezenove anos assumiu o cargo de carvoeiro contratado, depois de ter servido o exército por um ano. A fotografia (Figura 1) em que aparece diante da Locomotiva e do vagão repleto de carvão não só registrou o momento, mas também não deixou esquecer o trabalho pesado enfrentado durante os quatro anos (1949 - 1954) em que exerceu essa profissão.

Outro documento cuidadosamente guardado pela família chama atenção. Nele consta que Athanázio foi promovido ao cargo de Praticante de Escritório Classe Única, em 1954, por concurso público. Tudo indica que a ascensão profissional dentro da Rede Ferroviária significou muito para a família Almeida, que fez questão de deixar preservadas, no Museu, várias imagens

\footnotetext{
${ }^{34}$ LIMA, Solange Ferraz de; CARVALHO, Vânia Carneiro de. Cultura material e coleção em um museu de história: as formas espontâneas de transferência do privado. In: FIGUEIREDO, Betânia Gonçalves (Org.) Museus: dos gabinetes de Curiosidades à Museologia Moderna. Belo Horizonte: Argvmentvm; Brasília; CNPq, 2005. P. 94.
} 
nas quais Athanázio passou a se vestir impecavelmente, com terno, camisa branca e gravata preta, como demonstram as imagens fornecidas pela família.

Uma análise acurada de uma das fotografias (Figura 2) sugere pensar questões relativas às classes sociais e aos grupos étnicos. Por meio das vestimentas, do uso de determinados acessórios e no próprio gestual do grupo fotografado algumas ponderações se impõem.

óculos para leitura e escrita, relógios de pulso e uniformes/roupas alinhada(o)s compõem uma indumentária "adequada" aos contextos da época e da empresa na qual Sr. Athanázio trabalhava (Figura 2). Observando o ambiente em que os funcionários foram fotografados nota-se a presença de uma mesa espaçosa de madeira e um conjunto de quadros para possíveis anotações. Vários documentos/envelopes simetricamente dispostos perante os partícipes, na (suposta) reunião de trabalho, sugerem pensar que estaria acontecendo, naquele momento, uma eleição ou uma consulta/seleção de propostas, mas isso são apenas hipóteses... O que se pode afirmar com certeza é que, pela quantidade de papéis dispostos sobre a mesa, decisões importantes estavam sendo discutidas naquela tarde, ou manhã, da década de 1960, na Estação Ferroviária de Londrina.

Figura 1: Athanázio e sua locomotiva, na década de 1950

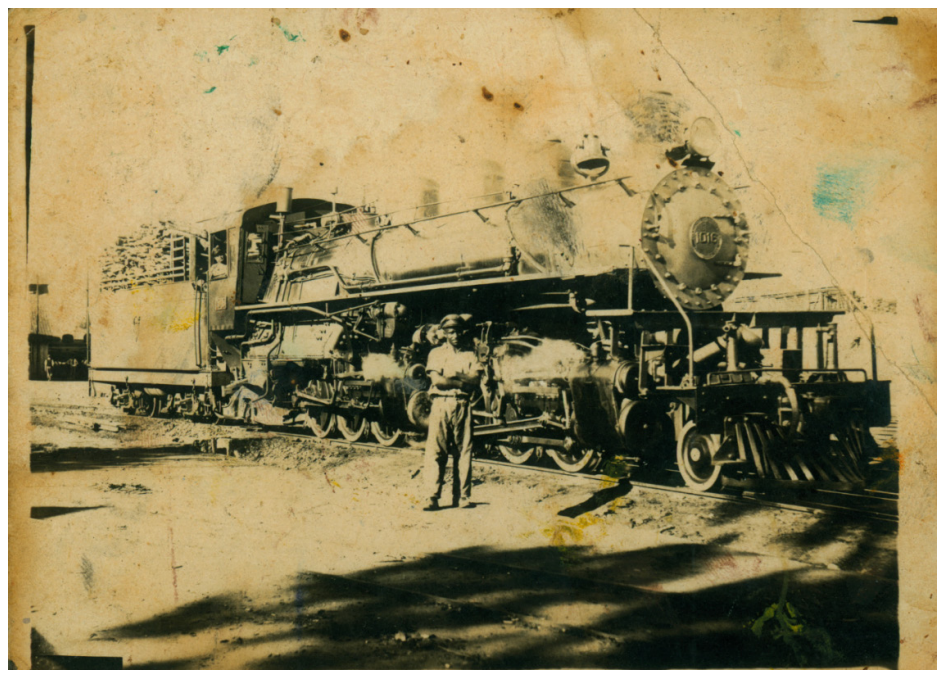

Fonte: Setor Imagem e Som - Eugênio Brugin, MHL. Reprodução digital, pxb, Jaguariaíva/PR.

A performance das personagens e a cultura material do ambiente, também, sinalizam algumas questões. Sobre a mesa, com canetas e cinzeiros, 
mãos e braços apoiados denotam uma postura corporal racionalizada, num ambiente de trabalho equilibrado e sistemático. Atitudes, características, gestos e posturas essas extremamente valorizadas no universo empresarial que, apesar da entrada da mulher no mercado de trabalho, permanecia, ainda, majoritariamente masculino e branco. Nesse sentido, importante observar que, dos doze homens localizados na fotografia, apenas dois eram negros. Um deles era o Sr. Athanázio que, curiosamente, olha diretamente para a câmera apresentando um sorriso discreto nos lábios. Postura e gestos esses diferentes daqueles observados na Figura 1, no qual Sr. Athanázio encontra-se em pé, de braços cruzados, ao lado da locomotiva onde, como já salientamos, exercia o cargo de carvoeiro.

Gilda de Mello e Souza, em o espírito das roupas, nos lembra que:

Um contraste não menos nítido que o da oposição dos sexos é o fornecido pela oposição de classes numa determinada sociedade, a qual tende a se revelar através de certos sinais exteriores como a vestimenta, as maneiras, a linguagem, chegando mesmo a refletir-se no modo pelo qual as pessoas se distribuem no espaço geográfico. ${ }^{35}$

Figura 2: Athánazio Soares de Almeida, o terceiro à esquerda, com um grupo de homens em reunião na Estação Ferroviária de Londrina (décadas de 1960/70)

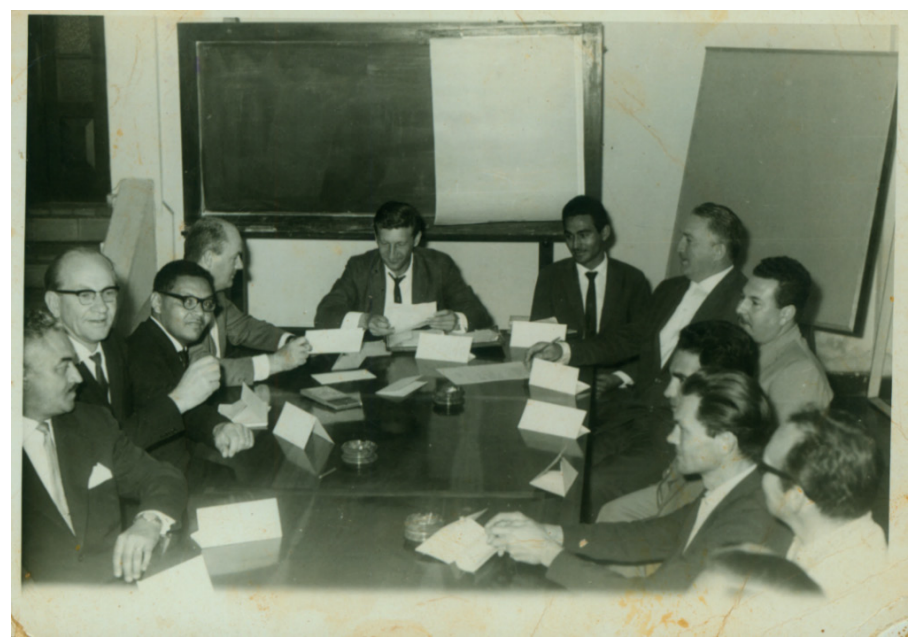

Fonte: Setor Imagem e Som - Eugênio Brugin, MHL. Reprodução digital, pxb, Londrina/PR.

\footnotetext{
${ }^{35}$ SOUZA, Gilda de Mello e. O espírito das roupas. A moda no século dezenove. São Paulo: Companhia das Letras, 1987. P. 111. Para um aprofundamento da questão referente à indumentária ver também o trabalho de ROCHE, Daniel. Cultura das aparências. Uma história da indumentária (séculos XVII e XVIII). São Paulo: Editora Senac São Paulo, 2007. Para os estudos que relacionam gênero e cultura material ver, principalmente: CARVALHO, Vânia Carneiro. Gênero e cultura material: uma introdução bibliográfica. In: Anais do Museu Paulista: História e Cultura Material. São Paulo. N. Ser. V. 8/9. 2003. p. 293/324.
} 
Além da desigualdade de gênero e classe social, apontadas por Gilda de Mello e Souza, podemos acrescentar que a imagem, disposta na Figura 2, deixou transparecer, também, a disparidade étnica presente naquele ambiente de trabalho. Atuar em uma empresa na qual a maioria dos funcionários era branca, em meados do século XX, não deve ter sido menos difícil do que a profissão de carvoeiro exercida anteriormente (Figura 1).

A segregação invisível, o preconceito velado, ou explícito, foram sentidos na pele e na alma. As palavras de seu obituário, publicadas no Jornal de Londrina pela família Almeida, revelam a luta empreendida pelos direitos dos negros em Londrina. ${ }^{36}$

\begin{abstract}
Athanázio lutou pelos direitos dos afro-descendentes
Athanázio Soares de Almeida nasceu no pequeno município de Jaguariaiva, no leste do Paraná, em 1964, mudou-se para Londrina com a família e cinco filhos pequenos. Começou a vida como foguista da Rede Ferroviária Federal Sociedade Anônima que cobria grande parte do território brasileiro. Pouco tempo depois conquistou um cargo no setor administrativo da companhia, onde se aposentou. Apesar de não ter terminado os estudos, sempre foi um leitor assíduo. Sofreu preconceitos velados, mas conseguiu superá-los, participando, inclusive, de movimentos de luta pelos direitos dos afrodescendentes. Athanázio Soares de Almeida morreu na segunda-feira e foi sepultado no Cemitério Padre Anchieta. ${ }^{37}$
\end{abstract}

Como é possível observar, são palavras e dizeres que as belas imagens concedidas pela família Almeida não puderam, ou não conseguiram, captar. Não sabemos se Athanázio conseguiu superar em vida os preconceitos velados, como alude o texto escrito para o obituário. A participação nos "movimentos de luta pelos direitos dos afrodescendentes" testemunhados pela família indica, no entanto, que não se rendeu aos preconceitos velados muitas vezes sofridos.

Assim como outros tantos homens e mulheres negros, o Senhor Athanázio teve seu nome escrito nas páginas do jornal apenas em razão de seu falecimento. A coleção da família Almeida em nada se parece com a de Miguel Calmon du Pin e Almeida, representante da fina e seleta oligarquia imperial, alijada do poder político com o advento da República. Regina Abreu, em estudo magistral, nos apresenta em detalhes a coleção do engenheiro e

\footnotetext{
${ }^{36} \mathrm{O}$ advogado Oscar do Nascimento, em depoimento cedido ao MHL, lembra que a AROL foi criada na década de 1950, com a finalidade de receber e auxiliar a sociedade negra na cidade, pois outras associações recreativas - como o Country Club de Londrina, criado pelos ingleses em 1934 - não acolhiam integralmente a comunidade negra. Esse fato também foi lembrado pelo músico e militar negro José Bispo dos Santos, entrevistado pelos funcionários do Museu Histórico de Londrina.
}

${ }^{37}$ JORNAL DE LONDRINA, 2007, grifos nossos. 
político doada, pela viúva Ana da Porciúncula Calmon du Pin e Almeida, ao Museu Histórico Nacional, em $1936 .{ }^{38}$ Entre os Calmon e os Almeida, havia um abismo - social e econômico.

Para a família do engenheiro da Primeira República (1889-1930), a coleção representava a consagração de uma vida luxuosa, repleta de "feitos e glórias" no campo político e econômico, conforme regulamentos e códigos sociais do final do século XIX e início do XX. Já para a família do carvoeiro-ferroviário levar as imagens do Sr. Athanázio para dentro de uma instituição museal, provavelmente, teve um forte apelo político e social. (In)conscientemente a doação desta coleção auxilia na construção de uma narrativa museal que possibilita problematizar a luta dos afrodescendentes contra as injustiças sociais.

Se as diferenças entre os dois exemplares, aqui escolhidos, são evidentes, um ponto, no entanto, conecta e une os Calmon e os Almeida para sempre. A doação de todo o material que se encontra hoje no Museu Histórico de Londrina e no Museu Histórico Nacional, constitui(u), aos olhos das respectivas famílias, a homenagem justa e apropriada - e também o desejo de eternizá-los. Ao adentrar as portas dos Museus que abrigam parte de suas histórias, cada um desses personagens, a seu modo, tornou-se imortal.

Em relação às coleções familiares do grupo social negro no Museu Histórico de Londrina, deve-se ressaltar que por se tratar de um acervo em construção muito ainda há que reunir e coletar. Observam-se, ademais, lacunas dignas de nota, como a ausência das mulheres no conjunto de coleções abrigadas até agora pela instituição.

\section{Considerações finais}

Ao analisar os meandros da trajetória do MHL e parte da história que envolve a formação de suas coleções, em especial aquelas destinadas às famílias negras, algumas considerações podem ser destacadas aqui. A despeito das dificuldades - falta de recursos, pessoal qualificado, etc...- enfrentadas pelos gestores da quarta fase do MHL, percebe-se que a instituição encontra-se, hoje, em sintonia com a Recomendação referente à Proteção e Promoção dos Museus e Coleções, sua Diversidade e seu Papel na Sociedade..$^{39}$

\footnotetext{
${ }^{38}$ ABREU, Regina. A fabricação do imortal. Memória e estratégias de consagração no Brasil. Rio de Janeiro: Rocco: Lapa, 1996.

${ }^{39} \mathrm{O}$ documento foi aprovado pela Conferência Geral da UNESCO em sua $38^{\mathrm{a}}$ sessão, em novembro de 2015. Ver: <https://www.museus.gov.br/wp-content/uploads/2016/11/Unesco_Recomendacao-Final_PORtraducao-nao-oficial.pdf>. Acesso em: 17 de agosto de 2018.
} 
Segundo o documento, "os museus e coleções contribuem ao aprimoramento dos direitos humanos, conforme definidos na Declaração Universal dos Direitos Humanos". ${ }^{40}$ Nesse sentido, e considerando as recomendações da UNESCO, a coleção do Sr. Athanázio constituiu, como se pôde perceber, um caso exemplar. A análise empreendida, aqui, permitiu o diálogo direto com os estudos que enfocam a formação de coleções, principalmente, aquelas antes negligenciadas ou discriminadas nas (e pelas) instituições museais.

Do mesmo modo, o caso selecionado e a abordagem empreendida possibilitaram contribuir com o amplo debate em curso que privilegia investigar a representação do passado em museus históricos. Representação essa que, até há poucas décadas atrás, desconsiderava sumariamente negros, indígenas, mulheres, crianças, idosos e, de modo geral, as vozes dos colonizados e dos "pioneiros" desprovidos de prestígio social e econômico, como a do Sr. Athanázio Soares de Almeida. ${ }^{41}$

Embora numericamente pequenas, qualitativamente fragmentadas e lacunares, as coleções de famílias negras, doadas recentemente, permitem nuançar temas relativos às desigualdades sociais, bem como as ações de preservação e a política de aquisição dos museus no Brasil, em especial aqueles que se dedicam aos acervos regionais, como é o caso do Museu Histórico de Londrina.

Cabe destacar, por fim, que:

Sobre os negros brasileiros, podemos dizer que eles ainda não cessaram de ser vencidos. Para irmos além da história dos vencedores, é preciso reconstituir os diversos processos históricos responsáveis pelos diversos mecanismos de exclusão e discriminação. ${ }^{42}$

Artigo recebido para publicação em 26/06/2018 Artigo aprovado para publicação em 06/09/2018

\footnotetext{
${ }^{40} \mathrm{Ibidem}$.

${ }^{41}$ A respeito das questões ideológica e política envolvendo a definição e conceito de "pioneiros" em Londrina ver, principalmente, o trabalho de Edson José Holtz Leme (2013) já citado aqui. Ver, também, os estudos de ADUM, Sônia Sperandio Lopes. Historiografia norte paranaense: alguns apontamentos. In: ALEGRO, Regina Célia, et al (Org.). Temas e questões para o ensino de história do Paraná. Londrina: EDUEL, 2013. P. 0126. ARIAS NETO, José Miguel. Discurso Político e Identidade Regional. História \& Ensino, Londrina: UEL, v.1, p.194-208, 1995.
}

${ }^{42}$ SANTOS, 2005, p. 40. 